\title{
An Overview of Advanced Elastomeric Seal Development and Testing Capabilities at NASA Glenn Research Center
}

\author{
Patrick H. Dunlap, Jr. ${ }^{1}$ \\ NASA Glenn Research Center, Cleveland, OH 44135
}

\begin{abstract}
NASA is developing advanced space-rated elastomeric seals to support future space exploration missions to low Earth orbit, the Moon, near Earth asteroids, and other destinations. This includes seals for a new docking system and vehicle hatches. These seals must exhibit extremely low leak rates to ensure that astronauts have sufficient breathable air for extended missions. Seal compression loads must be below prescribed limits so as not to overload the mechanisms that compress them, and seal adhesion forces must be low to allow the sealed interface to be separated when required (e.g., during undocking or hatch opening). NASA Glenn Research Center has developed a number of unique test fixtures to measure the leak rates and compression and adhesion loads of candidate seal designs under simulated thermal, vacuum, and engagement conditions. Tests can be performed on fullscale seals with diameters on the order of 50 in., subscale seals that are about 12 in. in diameter, and smaller specimens such as $\mathbf{O}$-rings. Test conditions include temperatures ranging from -238 to $662^{\circ} \mathrm{F}\left(-150\right.$ to $\left.350^{\circ} \mathrm{C}\right)$, operational pressure gradients, and seal-on-seal or seal-on-flange mating configurations. Nominal and off-nominal conditions (e.g., incomplete seal compression) can also be simulated. This paper describes the main design features and capabilities of each type of test apparatus and provides an overview of advanced seal development activities at NASA Glenn.
\end{abstract}

\section{Nomenclature}

$C B M=$ Common Berthing Mechanism

$G R C=$ Glenn Research Center

ISS $=$ International Space Station

LVDT = linear variable displacement transformer

$R T D=$ resistance temperature detector

$R T V \quad=$ room temperature vulcanizing

\section{Introduction}

$\mathrm{N}$ ASA is developing advanced space-rated vacuum seals in support of future space exploration missions to low Earth orbit, the Moon, near Earth asteroids, and other destinations. This includes seals for a new docking system and vehicle hatches (Figs. 1 and 2). These seals can be relatively large with diameters on the order of 50 in. $(127 \mathrm{~cm})$ and are typically made of elastomeric materials such as silicone. Seal leak rates must be extremely low to ensure that astronauts have sufficient breathable air for extended missions to the International Space Station (ISS) or the Moon, for example. Seal compression loads must be below prescribed limits so as not to overload the mechanisms that compress them, and seal adhesion forces must be low to allow the sealed interface to be separated without damage when required (e.g., during undocking or hatch opening).

NASA Glenn Research Center (GRC) has developed a number of unique test fixtures to measure the leak rates, compression loads, and adhesion loads of candidate seal designs under simulated thermal, vacuum, and engagement conditions. Tests can be performed on a variety of seal designs ranging from small O-rings less than an inch in diameter to full-scale seals that are approximately 50 in. in diameter. This paper describes the main design features and capabilities of each type of test apparatus and provides an overview of advanced seal development activities at NASA GRC.

\footnotetext{
${ }^{1}$ Mechanical Engineer, Materials and Structures Division, 21000 Brookpark Road.
} 


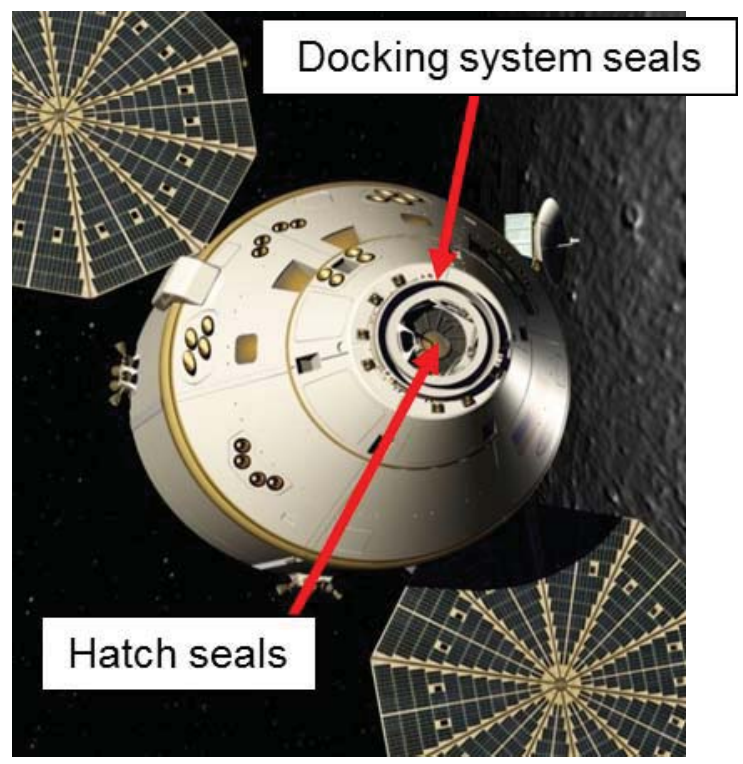

Figure 1. Locations for advanced seal designs on the Orion spacecraft.

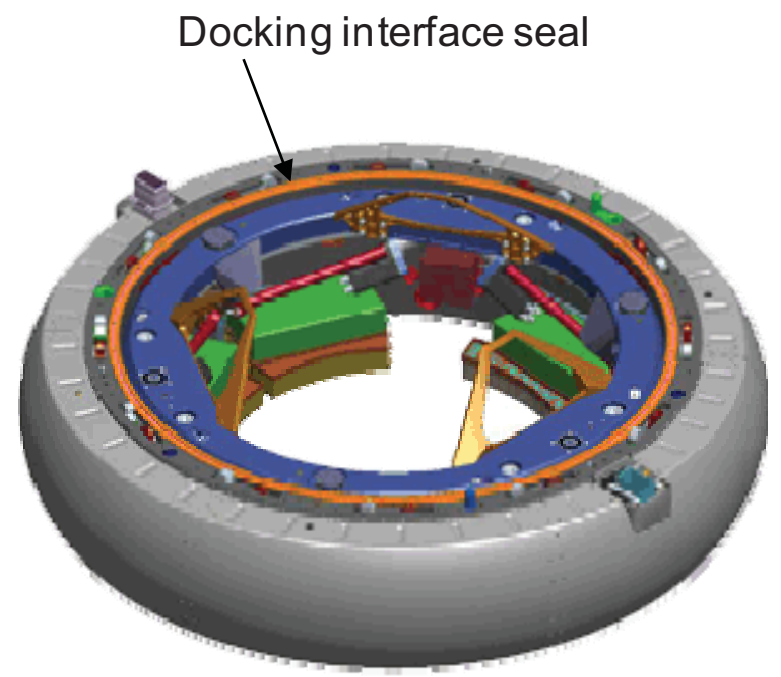

Figure 2. Docking interface seal location.

\section{Candidate Seal Designs}

Several different types of seal designs have been considered for these applications including Gask-O-seals, multi-piece seals, and O-rings. For each application, the seal design features are tailored to meet the requirements.

\section{A. Gask-O-Seals}

Gask-O-seals ${ }^{\circledR}$ are a type of seal produced by Parker Hannifin Corporation that are formed by molding silicone elastomer seals directly into the grooves of a metallic (e.g., aluminum) retainer to form a single-piece seal assembly. Each seal features a bulb in the center of the groove with voids on either side to allow the bulb to spread out when it is compressed. The seal bulb is sized to prevent the incompressible rubber from completely filling the groove when it is fully compressed. This design has space flight experience and has been used as a static seal in multiple locations on the ISS including seals for the Common Berthing Mechanism ${ }^{1}$ (CBM), windows, hatches, and electrical connectors.

Figure 3 illustrates the cross section of a candidate Gask-O-seal design that was considered for the docking interface seal location. ${ }^{2}$ This seal has dual bulbs on both the "front" and "back" sides of the retainer to meet seal 
redundancy requirements. The seal bulbs on the front side would be compressed during docking, and those on the back side would be compressed when the seal assembly is installed on the docking system tunnel. In the design shown in Fig. 3, the cross sections of the two front seal bulbs are identical. The back seal bulbs are also identical, although they are smaller than the front seals. However, the sizes and shapes of the seal bulbs could all be the same and can be tailored to meet the needs of a specific application.

This seal assembly was designed to be installed directly on the top of a docking system tunnel (Fig. 2) without requiring a separate groove or flange. Alignment pin holes in the retainer (not shown) are used to align the axes of the seal and the docking system tunnel during seal installation, and fasteners are used to attach the seal assembly to the top of the tunnel. Figure 4 shows a close up view of a 54-in. diameter seal installed in a leak test apparatus at NASA GRC.

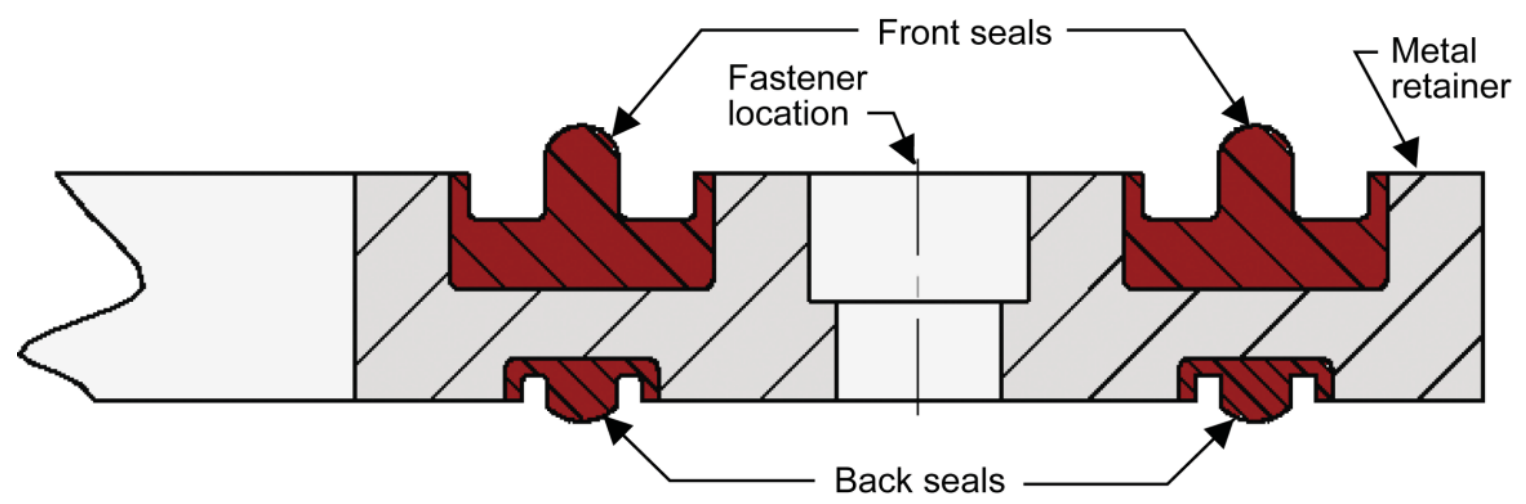

Figure 3. Cross section through Gask-O-seal showing silicone seals molded into grooves on front and back surfaces of metal retainer.

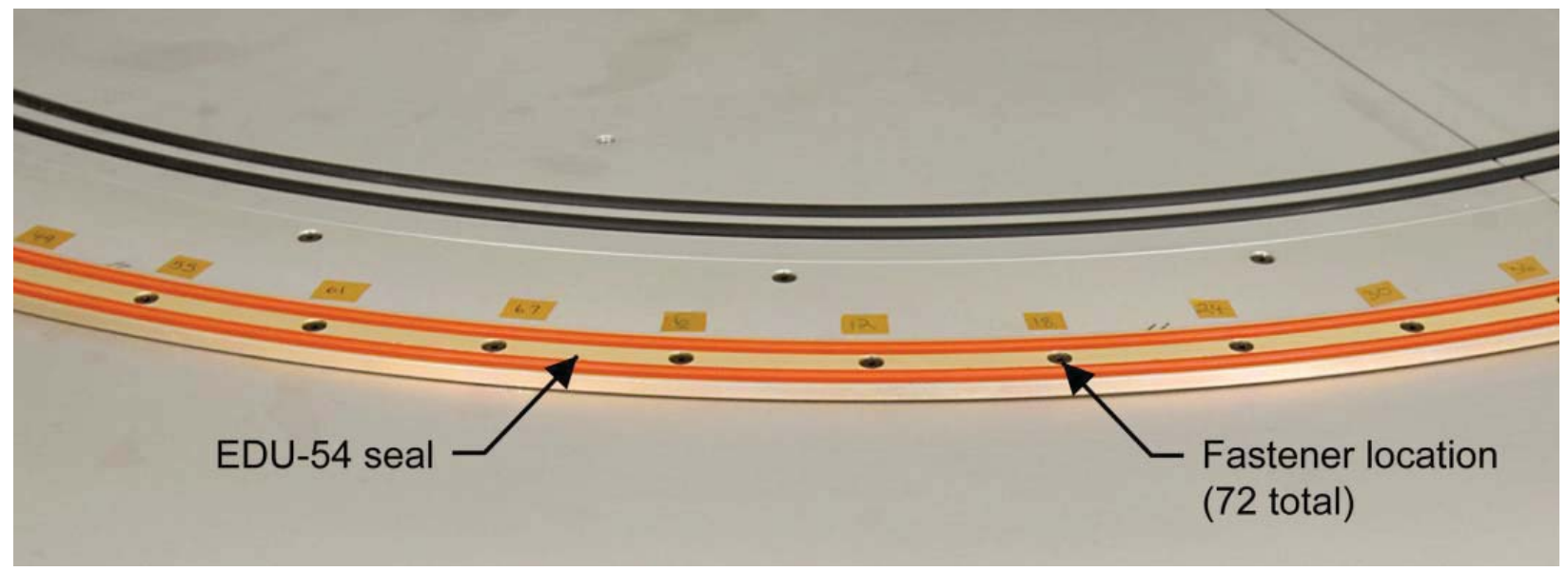

Figure 4. Photograph of 54-in. diameter (EDU-54) Gask-O-seal installed in test apparatus showing dual front seal bulbs and fastener holes.

\section{B. Multi-Piece Seal Design}

The multi-piece seal design consists of an elastomer element with two seal bulbs connected by a web and a separate metal retainer with periodic bosses that pass through openings in the web (Figs. 5 and 6). This seal design was developed specifically for the docking interface seal location. ${ }^{2}$ Whereas the Gask-O-seal would be installed directly on the top of a docking system tunnel, the multi-piece seal would be installed in a groove on the top of a tunnel. A series of fasteners secures the seal assembly to the base of the seal groove.

Like the Gask-O-seal design, the elastomer seal element is molded out of silicone and has two seal bulbs to satisfy redundancy requirements. However, unlike the Gask-O-seal, the metal retainer is a separate element (or elements for a multi-segment retainer), and the elastomer seal bulbs are not molded directly into it. The retainer in this design anchors the elastomer seal element to the tunnel and locates and centers the seal assembly in the tunnel groove. 


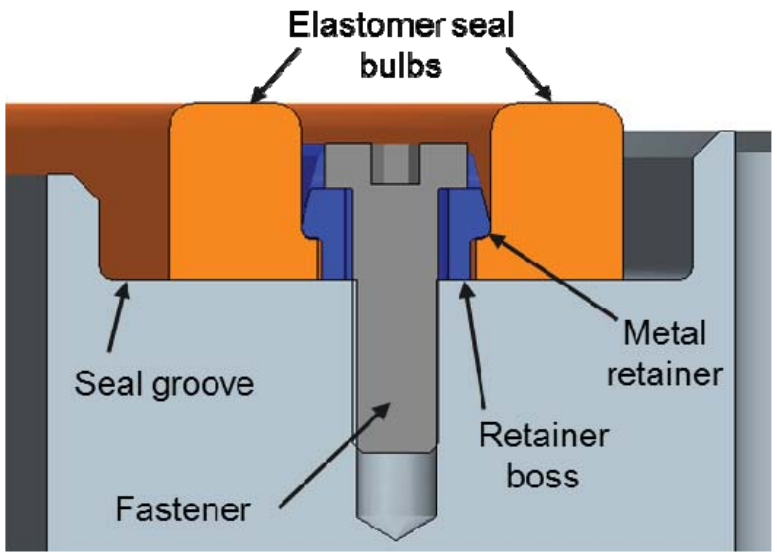

(a)

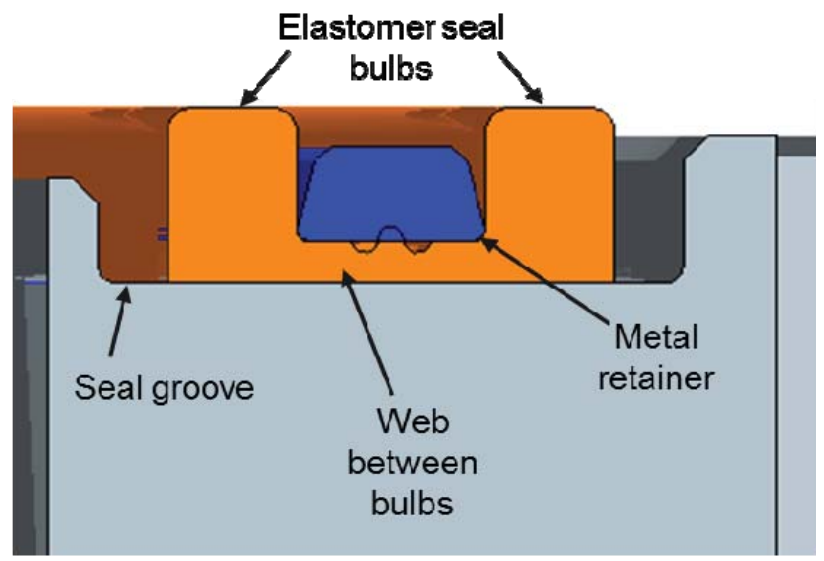

(b)

Figure 5. Cross section through multi-piece seal assembly (a) at fastener location and (b) at location between fasteners.

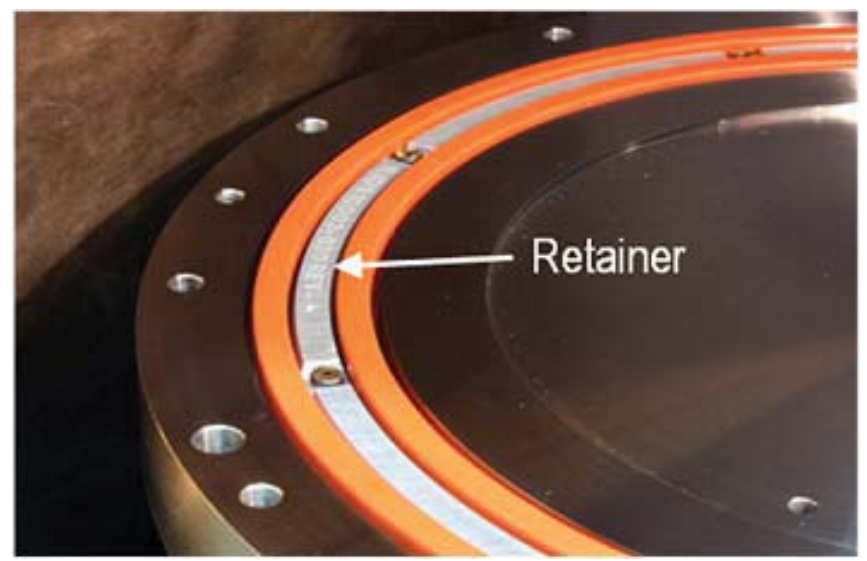

Figure 6. Photograph of subscale multi-piece seal installed in groove in test apparatus.

\section{O-Rings}

An O-ring is a torus, or doughnut-shaped ring, generally molded from an elastomer. ${ }^{3}$ O-ring seals of different sizes and materials have been evaluated by the GRC seal development team. Typically, small O-rings have been used for material screening tests to help select the final seal material for an application. ${ }^{4,5}$ However, larger O-rings have also been tested as potential seal designs for various applications.

\section{Key Seal Requirements that Influenced Test Fixture Designs}

To effectively evaluate the performance of candidate seal designs, test fixtures had to be developed that were capable of testing the seals under representative operating conditions. This section describes the key requirements that influenced the designs of the various seal test fixtures at NASA GRC. Most of these requirements were driven by the needs of the docking system project.

\section{A. Thermal Conditions}

Test fixtures had to be able to heat and cool the seal test specimens to simulate the thermal conditions they would experience during a mission. This includes seal mating (i.e., compression) and separation over a temperature range from -58 to $142^{\circ} \mathrm{F}\left(-50\right.$ to $\left.61^{\circ} \mathrm{C}\right)$. Once compressed, the seals then had to satisfy their leak rate requirement over a mated and pressurized temperature range of -22 to $133^{\circ} \mathrm{F}\left(-30\right.$ to $\left.56^{\circ} \mathrm{C}\right)$. 


\section{B. Mating Conditions and Interface Characteristics}

As the design for the docking system evolved, the ability to support two different mating configurations was considered. Docking could occur in an androgynous seal-on-seal configuration in which both sides of the interface have seals installed or in a seal-on-flange configuration with a seal on one side of the interface and a flat, smooth metal flange on the other side. ${ }^{2}$ Seal-on-flange mating would occur when a vehicle with a seal installed on its docking system docks to a node on the ISS with a flat metal flange. Seal-on-seal mating would occur when two vehicles equipped with seals on their docking systems dock to each other. Figure 7 illustrates both of these configurations. Because seal mating could occur in either a seal-on-seal or seal-on-flange configuration, the test fixtures had to be capable of performing tests in both mating arrangements.

To achieve vacuum level sealing, a maximum surface roughness of $16 \mu$ in. $(0.41 \mu \mathrm{m})$ has been recommended. ${ }^{3}$ Therefore, sealing surfaces on the test fixtures had to have surface finishes of $16 \mu \mathrm{in}$. or better. The sealing surfaces on both sides of the interface also had to be precisely aligned so that the amount of compression on the seal test specimens could be carefully controlled.
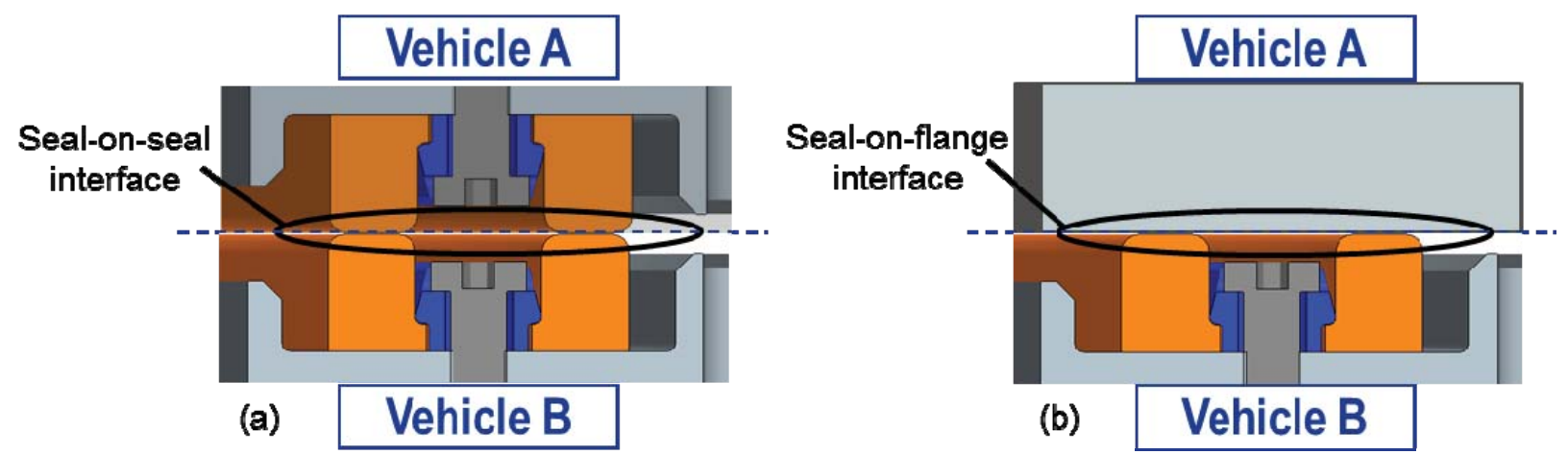

Figure 7. Cross sections through the interface between two mated systems showing (a) seal-on-seal mating and (b) seal-on-flange mating.

\section{Use of Redundant Sealing Features}

Manned space systems require that all seal locations with diameters larger than $6.0 \mathrm{in} .(15 \mathrm{~cm})$ have a minimum of two seals for redundancy. Because of this, seals for future docking systems and hatches will include redundant sealing features. This allows the sealed interface to be single fault tolerant wherein it can still satisfy the leak rate requirement even if one of the seals has been compromised. To address this requirement, seal leak test fixtures had to be capable of testing each seal individually.

\section{Leak Rate}

The most important function for a space-rated vacuum seal is to minimize leakage across the sealed interface. Test fixtures and their associated instrumentation must be able to measure seal leak rates at a nominal pressure differential of 14.7 psid across the range of temperatures noted earlier. Under these conditions, acceptable seal leak rates were expected to be on the order of $1 \times 10^{-4}$ to $1 \times 10^{-2} \mathrm{lbm}$ dry air/day thereby requiring accurate leak measurement systems.

\section{E. Compression and Adhesion Loads}

The test fixtures had to be able to compress seal test specimens under the specified thermal conditions and measure the mechanical loads generated by the compressed seals. Depending on the seal design and size, forces up to $100 \mathrm{lbf}$ per in. ( $175 \mathrm{~N}$ per $\mathrm{cm}$ ) of seal were anticipated resulting in total compression loads on the order of 35,000 to 40,000 lbf for a pair of seals approximately $60 \mathrm{in}$. in diameter. In addition, actuation systems for the test fixtures had to maintain the seals in a compressed state with the cavity inboard of the seals potentially pressurized for a leak test. Since seal adhesion forces were also of interest, test fixtures had to be capable of measuring the amount of load required to unload and separate a seal test specimen from its mating surface at the end of a compression test or between compression cycles. Seal adhesion forces as low as several pounds were anticipated for subscale seals. 


\section{F. Engagement Conditions}

Under certain conditions, seals may not be fully compressed when they are mated resulting in metal-to-metal joint separation (or "gapping") at the sealing interface. Periodic gapping can also occur between the mechanisms that compress the seals (e.g., latches) due to flange deflections around the perimeter of the sealing surface. To simulate these conditions, test fixtures had to be capable of testing seals in either a fully compressed condition or in a partially compressed state.

During seal-on-seal mating, the sealing surfaces on each side of the interface will likely not be perfectly radially aligned during mating due to manufacturing and assembly tolerances and differences in temperatures between mating surfaces. Test fixtures had to be able to evaluate seals in both aligned and misaligned configurations to address this requirement.

\section{Small-Scale Test Fixtures}

As noted above, O-rings and other small material samples have often been used for material screening tests to help select the final seal material for an application. This section describes the test fixtures that were developed to perform tests on these types of test specimens.

\section{A. Small-Scale Seal Leak Test Fixtures}

NASA GRC has several versions of test fixtures that are used to perform leak tests on small O-rings. Figure 8 shows one example of such a fixture. The O-ring test specimen is typically installed in a standard O-ring groove and compressed against a smooth, $16 \mu \mathrm{in}$. counterface. The test plates are made of either anodized aluminum or stainless steel. Near-hermetic plumbing and valves and the necessary measurement instruments (i.e., pressure transducers, thermocouples) are attached to the test plates. Tests can be performed on fully-compressed seals or under partially compressed (i.e., gapped) conditions by inserting precision shims between the test plates. Leak tests can either be performed on a laboratory bench top or inside a Tenney Benchmaster BTCR environmental control chamber (Fig. 9). The chamber is capable of cooling or heating the test article from -238 to $1122^{\circ} \mathrm{F}\left(-150\right.$ to $\left.600^{\circ} \mathrm{C}\right)$ with an accuracy of $\pm 0.2^{\circ} \mathrm{F}$. Controlled "room temperature" tests can also be performed inside the chamber at a regulated temperature of $73^{\circ} \mathrm{F}\left(23^{\circ} \mathrm{C}\right)$.

Leak rates are typically measured for a nominal pressure differential across the seal test specimen of $14.7 \mathrm{psid}$. This can be accomplished by pressurizing the volume inboard of the O-ring with dry air to a nominal $2 \mathrm{~atm}$ and allowing it to leak across the seal to ambient laboratory pressure or by pressurizing the inboard volume to $1 \mathrm{~atm}$ and evacuating the region outboard of the test specimen. Leak tests are performed using a pressure decay methodology, and the leak rate of each test specimen is quantified using the mass point leak rate technique with comprehensive error analysis. ${ }^{6,7}$

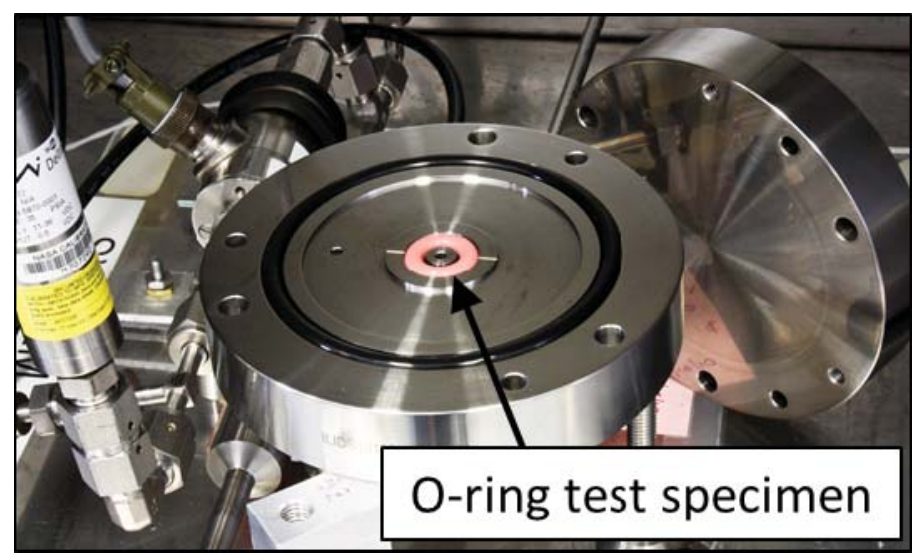

Figure 8. O-ring test specimen installed in leak test fixture. 


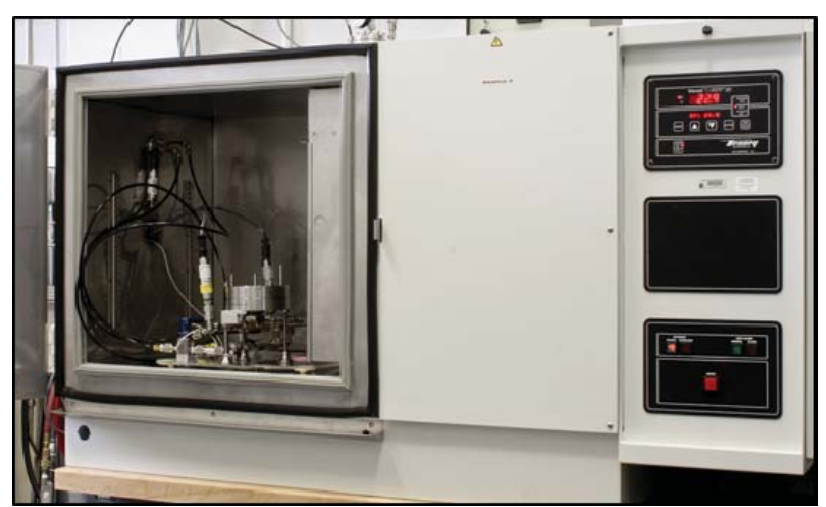

Figure 9. O-ring leak test fixture installed in environmental control chamber.

\section{B. Small-Scale Seal Compression and Adhesion Test Fixture}

For cost and efficiency considerations, small-scale, cylindrical "button" test specimens are often used for material screening tests (Fig. 10). These specimens are cut out of sheets of candidate seal materials and used for compression and adhesion testing.

Figure 11 shows the test apparatus used for these tests. ${ }^{8}$ Test specimens are typically attached to metallic holders using cyanoacrylate adhesive and allowed to cure for 24 hours before testing (Fig. 10). For seal-on-seal tests, one test specimen and its holder are attached to a stationary load cell, and the other specimen and holder are attached to a moveable platform. For seal-on-flange tests, one of the two test specimens is replaced by a clean, smooth (e.g., 16 $\mu$ in.), flat plate. A servomotor is used to move the platform to compress the specimens, hold them in a compressed state for the desired dwell period, and then move the platform back to unload them. The rate and amount at which the specimens are compressed can be programmed to follow a prescribed function of the distance between the two specimen surfaces. A linear variable displacement transformer (LVDT) is used to measure the amount of compression on the test specimens, and a load cell measures the resulting compression and adhesion loads. All tests are performed at room temperature.

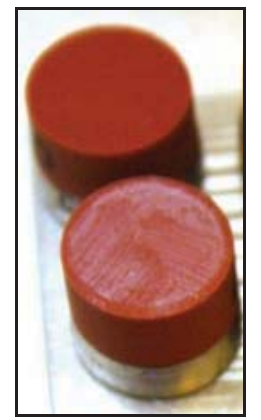

Figure 10. Small-scale, cylindrical "button" test specimens.

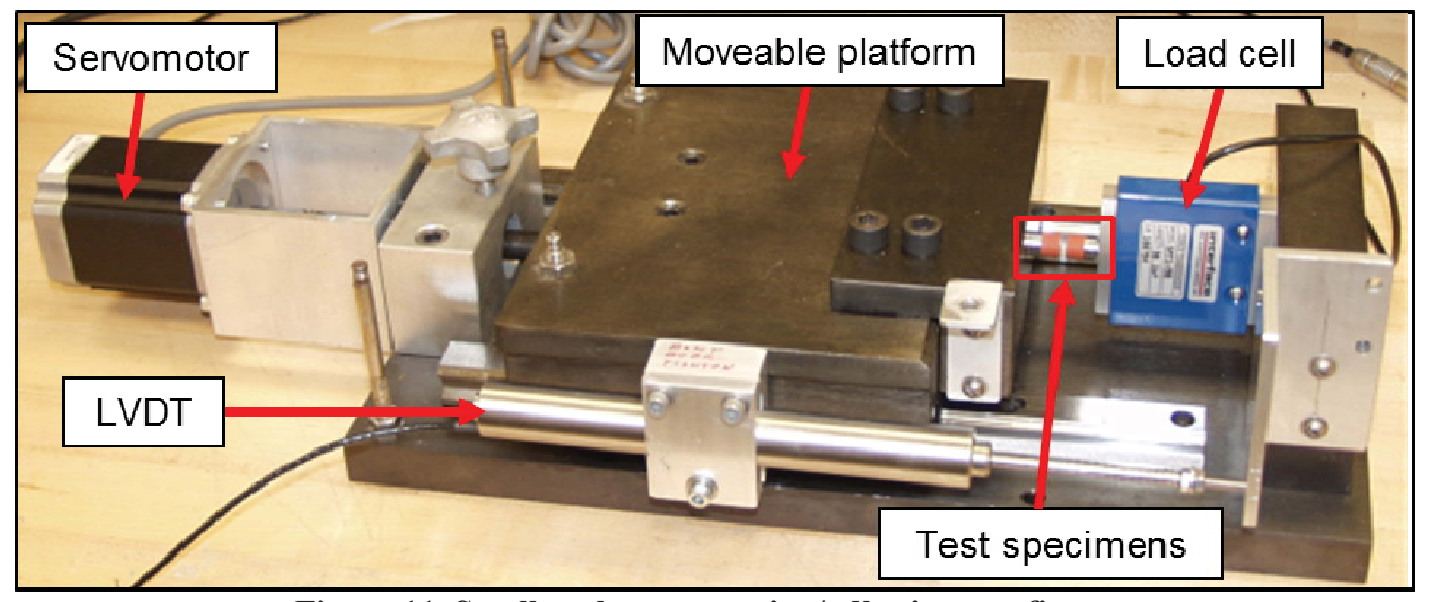

Figure 11. Small-scale compression/adhesion test fixture.

American Institute of Aeronautics and Astronautics 


\section{Medium-Scale Test Fixtures}

NASA GRC's medium-scale seal test fixtures are typically used to test subscale versions of larger seal designs. However, they can also be used to test other seal designs that are on the order of 12 in. in diameter. Advantages for testing subscale versions of larger seals include:

- Able to perform tests at a smaller scale that may be too difficult to perform at a larger scale

- Less expensive test specimens and test hardware

- Faster turnaround on testing

- Able to scale results to full-scale

This section describes the test fixtures that were developed to perform tests on medium-scale seal test specimens.

\section{A. Medium-Scale Seal Leak Test Fixtures}

Leak tests are performed on medium-scale seals in the test apparatus shown in Figs. 12 and 13. In this setup, a test fixture consisting of two anodized aluminum or stainless steel plates, near-hermetic plumbing and valves, and the necessary measurement instruments is installed into a Tenney Benchmaster BTCR environmental control chamber (Fig. 13). As noted earlier, the chamber is capable of cooling or heating the test article from -238 to $1122^{\circ} \mathrm{F}$ ( -150 to $600^{\circ} \mathrm{C}$ ) with an accuracy of $\pm 0.2^{\circ} \mathrm{F}$. Pressure transducers with a full-scale accuracy of better than $0.75 \%$ at a range of $0-35$ psia are attached to the control volume to monitor pressure, and resistance temperature detectors (RTDs) with an accuracy of $\pm 0.2^{\circ} \mathrm{C}$ monitor the temperature of the plates with the assumption that the temperature of the gas is identical to that of the plates.

Tests can be performed in either a seal-on-flange or seal-on-seal configuration. For seal-on-flange testing, the seal is installed in the lower test plate (Fig. 12) and compressed against a flat, smooth $16 \mu$ in. counterface on the upper plate. For seal-on-seal testing, seal test specimens are installed in both the lower and upper plates and compressed against each other. Tests can be performed on fully compressed or partially compressed seals by inserting precision shims between the test plates to set the amount of gapping. For seal-on-seal configurations, tests can be performed under aligned or misaligned conditions using alignment pins to position the upper plate with respect to the lower plate.

Leak tests can be performed using either air or helium as the test gas. Ports inboard, outboard, and between the seal bulbs allow the leak rate for either seal to be measured with a nominal pressure differential of 14.7 psid across it with the pressure source inboard of the seal and vacuum conditions on the outboard side. Air leak tests are performed using a pressure decay methodology, and the leak rate of each test specimen is quantified using the mass point leak rate technique with comprehensive error analysis. ${ }^{6,7}$ For helium leak tests, seal leak rates are measured directly using a helium leak detector. Since the inner and outer seal bulbs are of different diameters, the resulting leak rates can be normalized by the linear centerline circumference of the seal bulb under test so that comparisons can be made between tests performed on different bulbs and so that results can be scaled to full-scale.

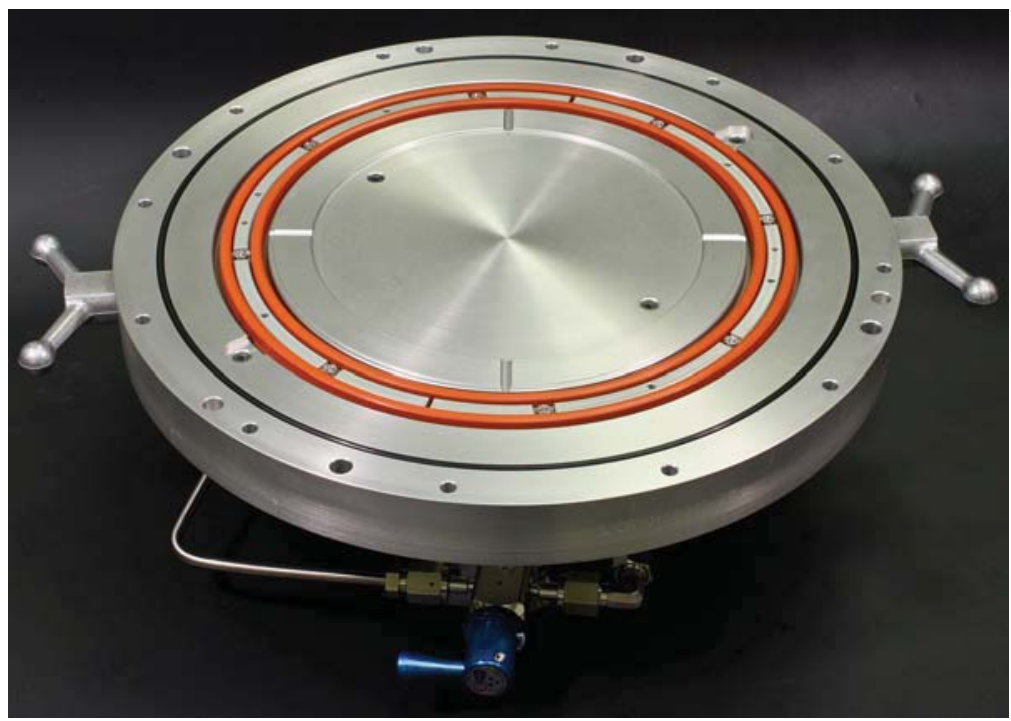

Figure 12. Medium-scale seal leak test fixture. (Note: Top of test fixture is not installed.) 


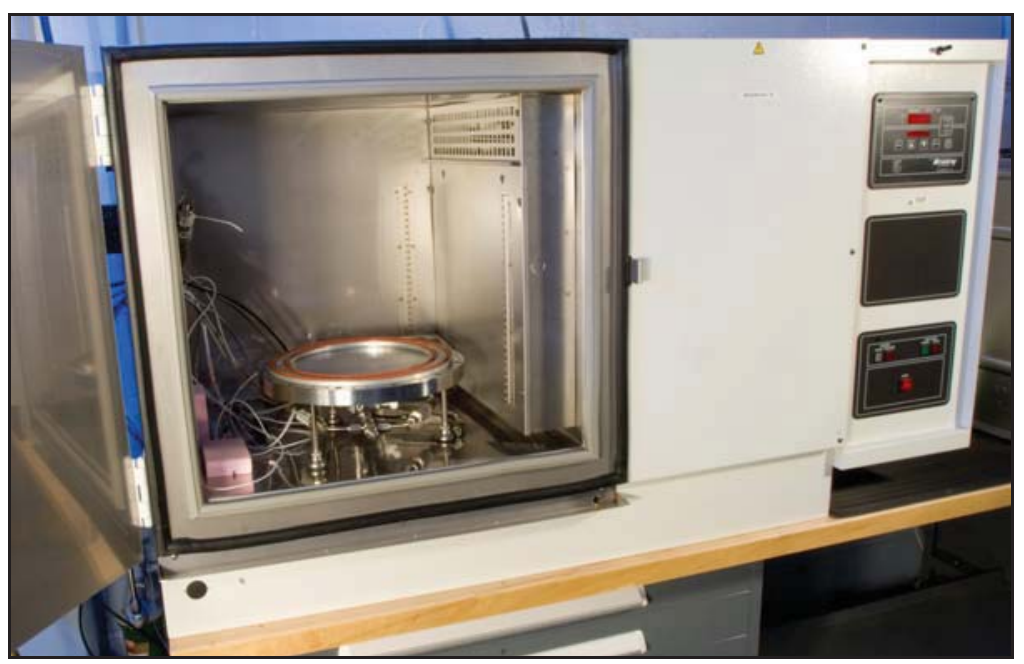

Figure 13. Medium-scale seal leak test fixture installed in environmental control chamber.

\section{B. Medium-Scale Seal Compression and Adhesion Test Fixtures}

Compression and adhesion tests are performed on medium-scale seals in the test apparatus shown in Fig. 14. Typically, seal compression and adhesion loads are both measured during each load cycle with the peak compression load occurring approximately when metal-to-metal contact of the test platens occurs and the peak adhesion load occurring when a seal test specimen is completely unloaded at the end of a load cycle.

The main components of this setup are an Instron Model 5584 electromechanically actuated material test system, an Instron 3119-407 environmental control system, and the test fixture platens that hold and compress the seals. The load frame is capable of generating loads up to $12,500 \mathrm{lbf}$ while following programmable loading and unloading profiles. Seal compression and adhesion loads are measured using an Interface 1020ACK-12.5K-B load cell with uncertainty better than $\pm 0.99 \%$ in compression and $\pm 0.55 \%$ in tension (i.e., adhesion). The environmental chamber is capable of cooling or heating the test specimens from -238 to $662^{\circ} \mathrm{F}\left(-150\right.$ to $\left.350^{\circ} \mathrm{C}\right)$ during a test. An MTS model LX300 laser extensometer mounted outside the environmental chamber is used to measure the displacement between the test platens which corresponds to the amount of compression on the seal test specimens. The test platens are similar to those used for the medium-scale seal leak tests, and they allow either seal-on-flange or seal-on-seal tests to be performed. Additional details on this test apparatus can be found in references 9, 10, and 11.

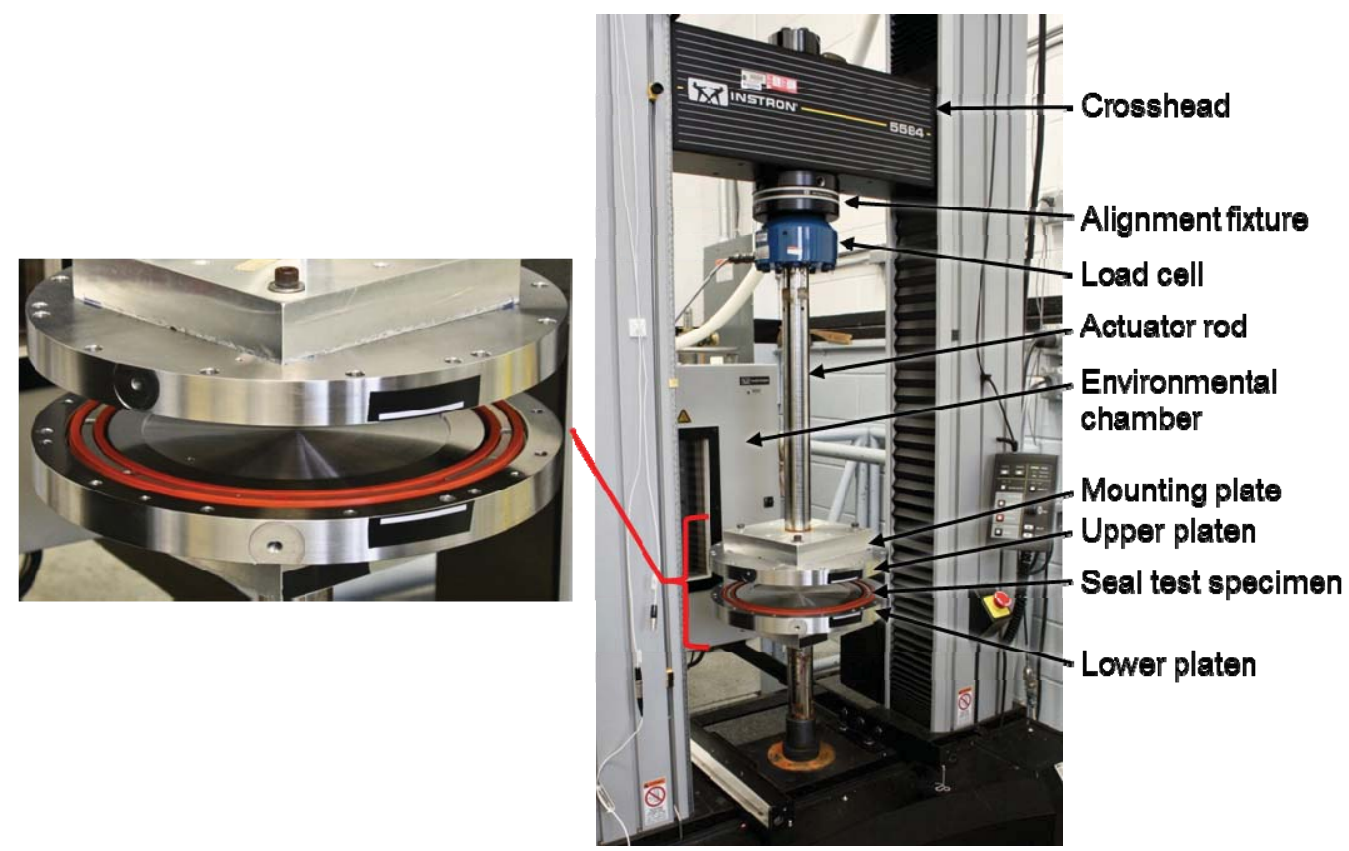

Figure 14. Test apparatus used for medium-scale seal compression and adhesion tests. 


\section{Medium-Scale Seal Pull-Out/Bond Strength Testing}

During undocking or hatch opening, it is possible for seal adhesion loads to be high enough that the seal could be pulled out of its groove (Fig. 15). This is an undesirable situation because the seal could be damaged in the process and would need to be replaced for future use. Also, debris from the liberated seal could damage other nearby hardware.

To evaluate this phenomenon and quantify the force required to remove a seal from its retaining feature at representative operating temperatures, a unique test setup was developed using the same load frame and environmental chamber that are used for medium-scale seal compression and adhesion tests. For these tests, a seal test specimen is installed in the lower seal test plate. A custom ring is then installed on the upper plate to allow "gripping" of the seal without pinching or squeezing it (Fig. 16a). The ring is then bonded to the top surface of the seal using a room temperature vulcanizing (RTV) silicone adhesive. The ring is designed to match the seal surface profile in order to maximize the area available for bonding with the RTV. After the RTV has cured, the upper surface is raised (Fig. 16b), and the amount of force required to pull the seal out of its groove is measured.

This testing configuration has been used to measure the amount of force required to pull Gask-O-seal bulbs out of their grooves ${ }^{12}$ and to separate a multi-piece seal bulb from its web. Additional details on this test setup can be found in the paper by Conrad et al. ${ }^{12}$

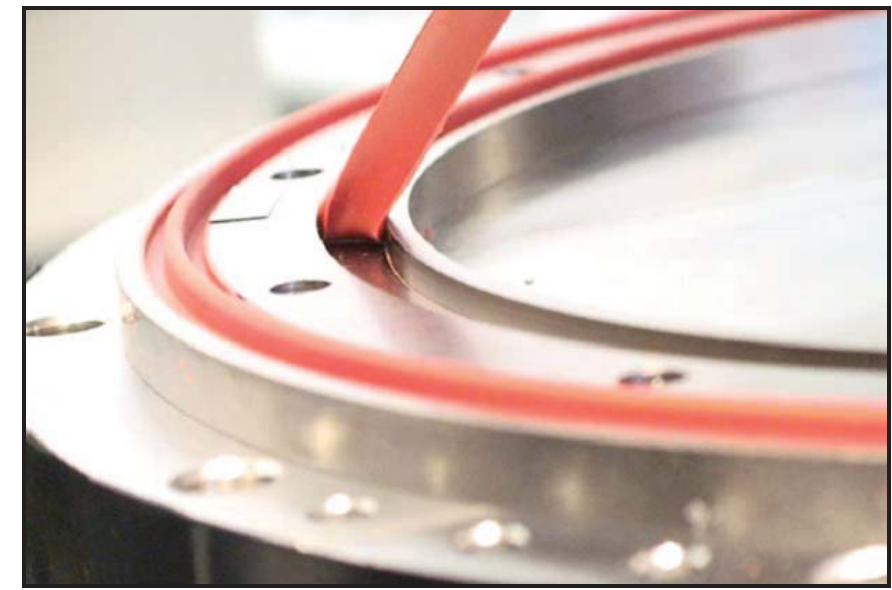

Figure 15. Gask-O-seal bulb being pulled out of its retainer during bond strength test.
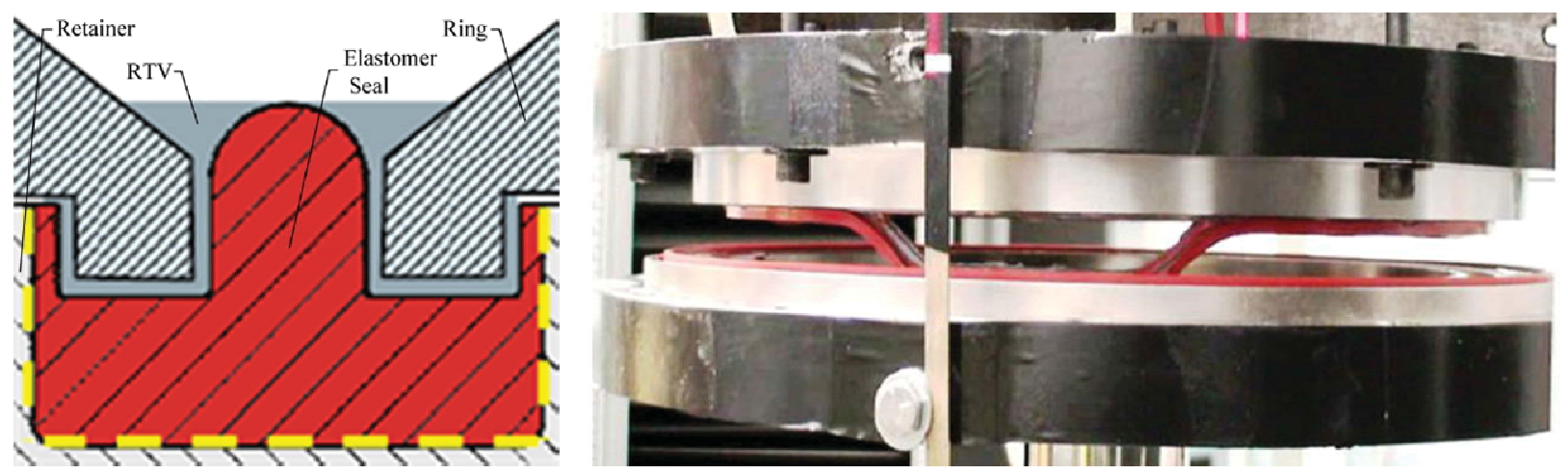

(a)

(b)

Figure 16. Test fixture used to perform seal pull-out/bond strength tests including (a) cross section through model of test fixture showing how ring is bonded to top surface of Gask-O-seal bulb and

(b) photo during a test. 


\section{Medium-Scale Seal Durability Testing}

During a mission it is possible for seals to be subjected to lateral movements in which they are scrubbed from side to side against the opposing sealing surface. These movements can occur as two sealing surfaces align with each other mechanically after initial engagement or as they thermally equilibrate after mating has completed.

To evaluate the effects of these lateral, scrubbing movements on seal performance, a medium-scale seal durability test rig was developed. The test plates in this rig were designed so that adhesion tests and leak tests could be performed on a seal before and after it was scrubbed against a mating surface without having to remove it from the test plates. In doing so, the effects of scrubbing on seal adhesion and leak rates could be evaluated while minimizing handling and disturbances of the seal in between each different type of test.

The test apparatus used for the seal durability tests is shown in Figs. 17 and 18. After baseline adhesion and leak tests are performed on a test specimen in separate test rigs, the test fixture is integrated into the durability test apparatus. The amount of compression on the seals is controlled by a set of eight standoff posts on top of which precision metal shims are installed. Contact between the upper and lower platens is avoided so as not to rub them against each other during a test. The upper test platen is secured to the base of the test apparatus through the standoffs and remains fixed during testing. The lower test platen is mounted on a pair of linear rails and connected to a screw jack assembly. This allows the lower platen to be moved back and forth along the rails when the screw jack is turned by hand, thereby scrubbing the seals against the fixed upper platen. Test specimens can be subjected to multiple scrub cycles during a test. The movement of the lower test platen is measured by a U.S. Digital PE-500-2-ID-D linear probe encoder with a 2 in. $(50.8 \mathrm{~mm})$ travel and an accuracy of $0.0005 \mathrm{in} .(0.0127 \mathrm{~mm})$.

This test apparatus was designed to perform tests at temperatures up to $142^{\circ} \mathrm{F}\left(61^{\circ} \mathrm{C}\right)$. To achieve these elevated temperatures, the upper and lower test platens are heated by Omega SRFR-7/5-P round silicone rubber heaters mounted on the back sides of the test platens. A Type K thermocouple installed in each platen is used to control and monitor the heater temperatures. Insulation plates installed behind both the upper and lower seal test platens help maintain them at the desired temperature during testing. Additional details on this test apparatus can be found in the paper by Dunlap et al. ${ }^{13}$
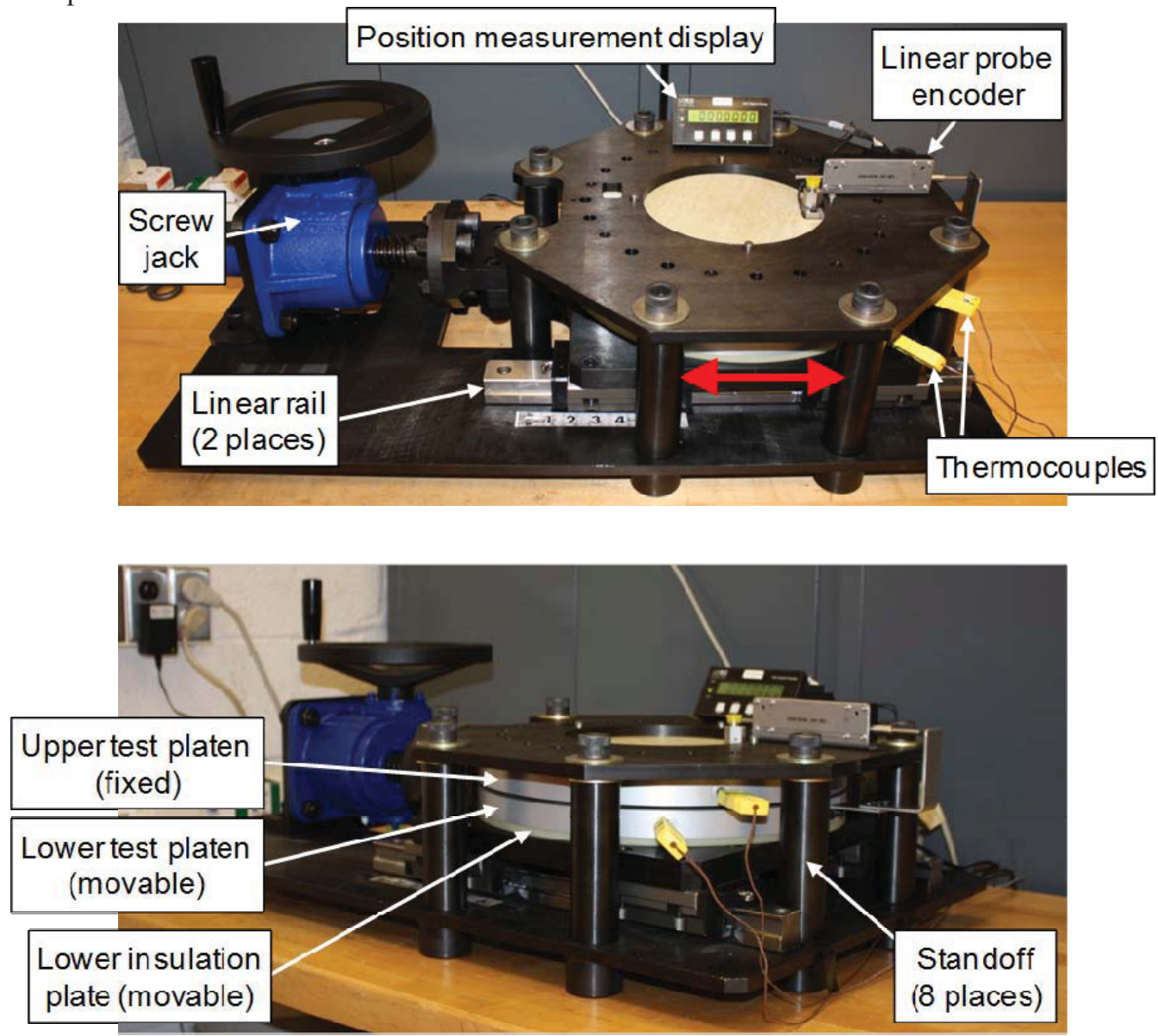

Figure 17. Main components of seal durability test apparatus.

11

American Institute of Aeronautics and Astronautics 


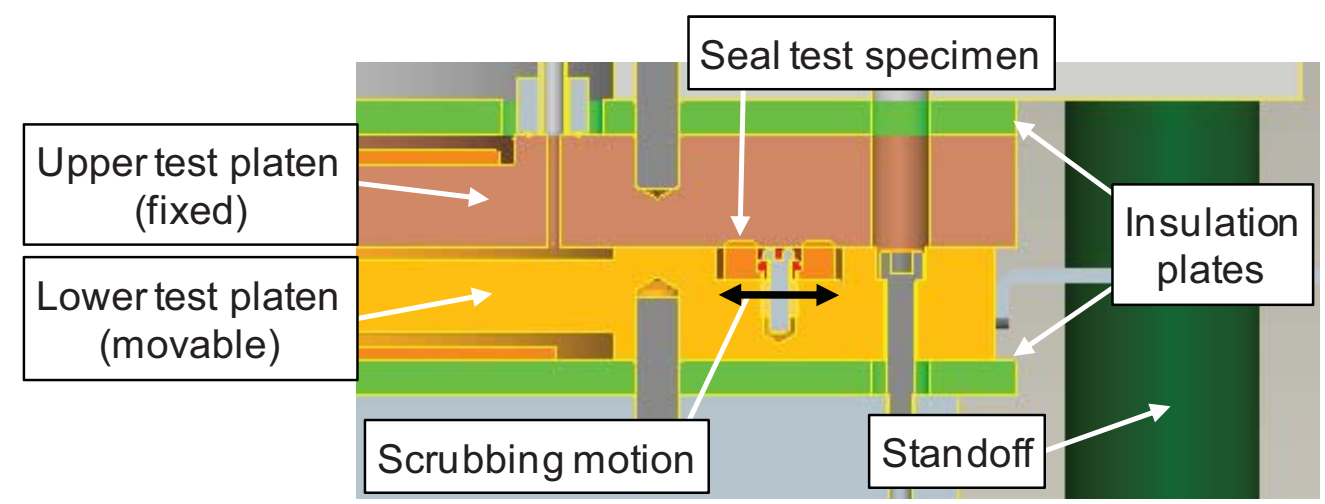

Figure 18. Cross section through seal durability test apparatus showing seal test specimen and scrubbing motion.

\section{Full-Scale Test Fixtures}

While subscale testing can provide valuable information for material screening and seal performance trends, the ultimate goal is to evaluate full-scale seal performance under representative operating conditions. To achieve this goal, NASA GRC has developed two unique full-scale seal test fixtures.

\section{A. Full-Scale Seal Leak Test Fixture}

Full-scale seal leak tests are performed in the test apparatus shown in Fig. 19. The main elements of this test setup are the upper and lower test assemblies (Fig. 20) both of which are made of anodized aluminum. For seal-onflange testing, the seal test specimen is installed in the lower test assembly (Fig. 21), and the flat, $16 \mu$ in. sealing surface is on the upper assembly. For seal-on-seal testing, a different upper test assembly is used with a seal installed in it. Tests can be performed on fully compressed or partially compressed seals by inserting precision shims between the test assemblies to set the amount of gapping. For seal-on-seal configurations, tests can be performed under aligned or misaligned conditions using alignment pins to position the upper assembly with respect to the lower one.

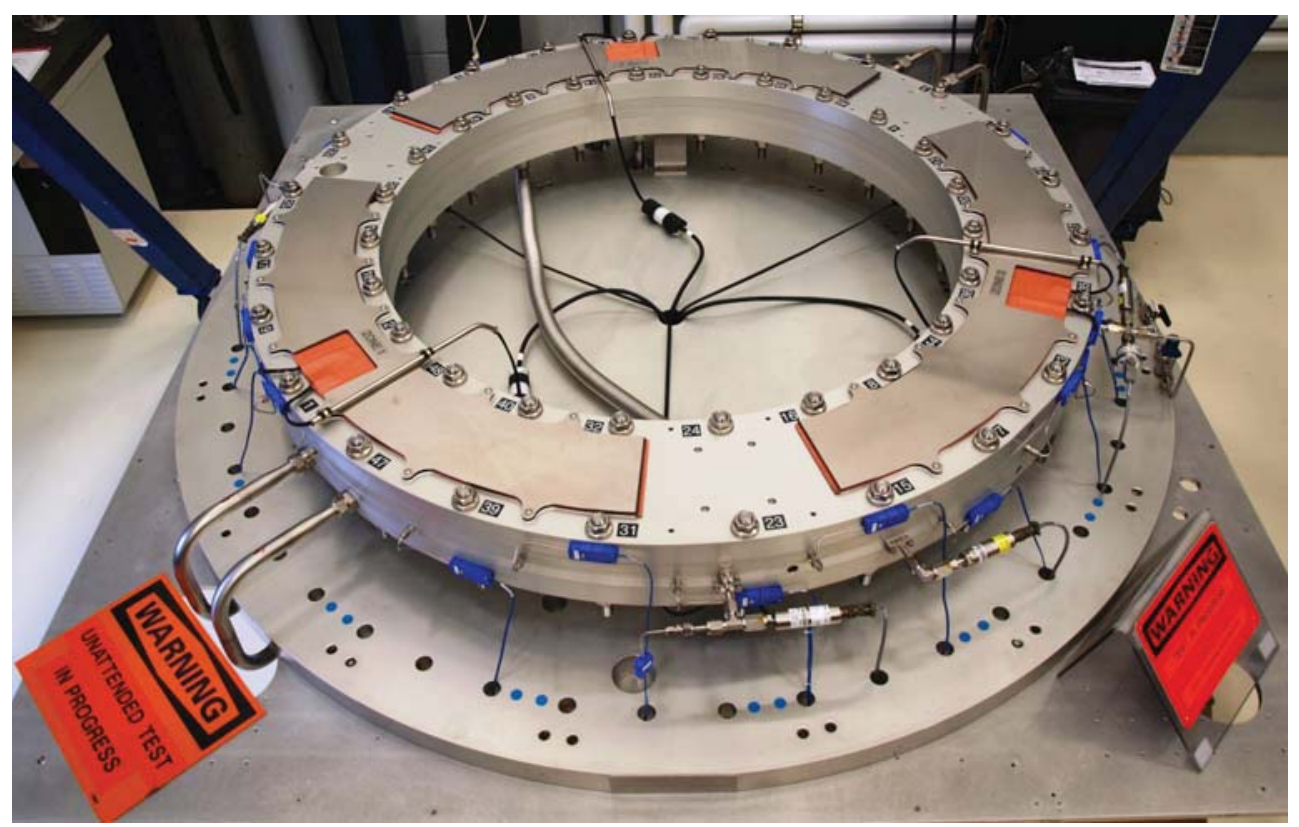

Figure 19. Full-scale seal leak test fixture. 


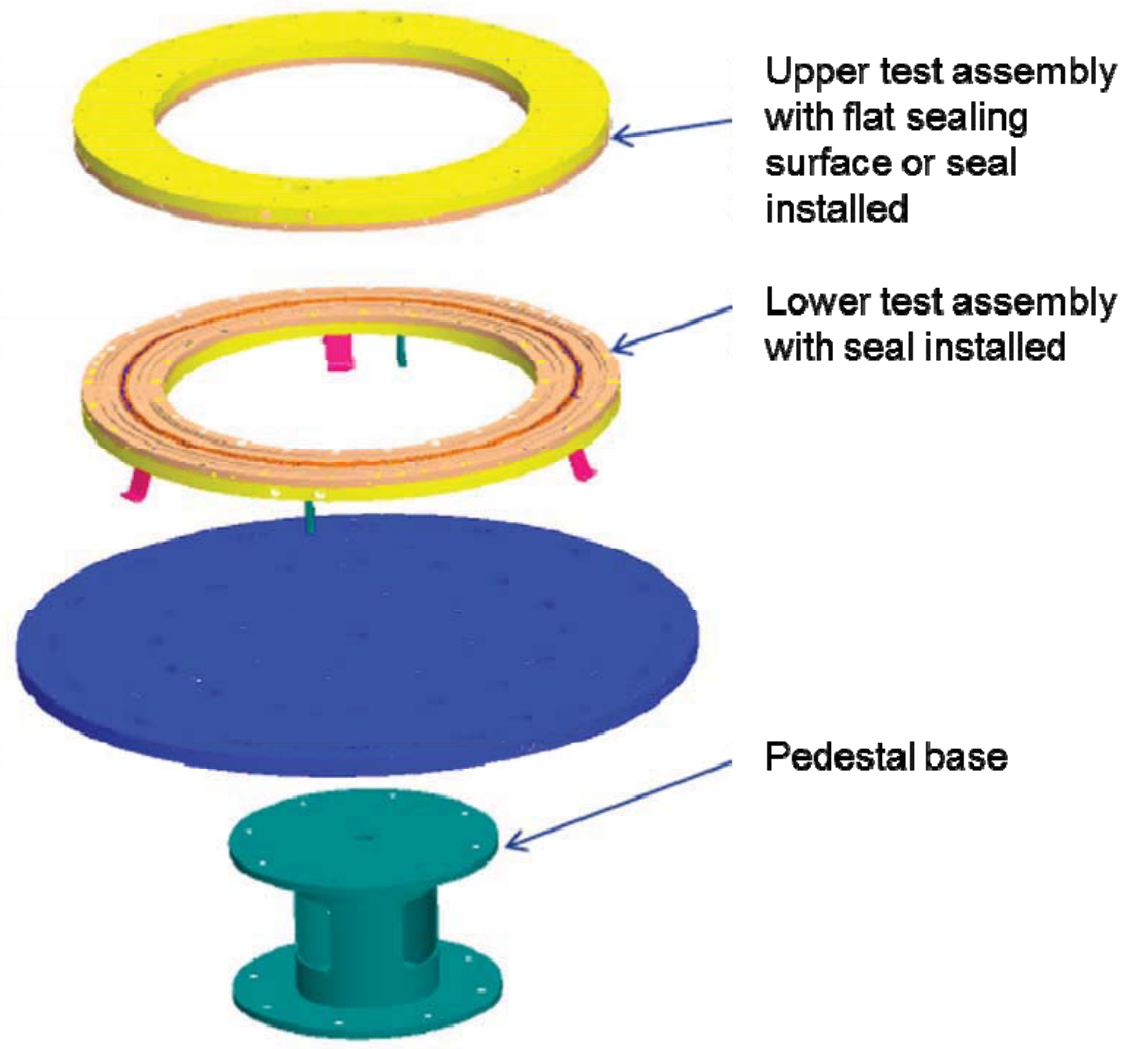

Figure 20. Exploded view of full-scale seal leak test fixture showing main elements.

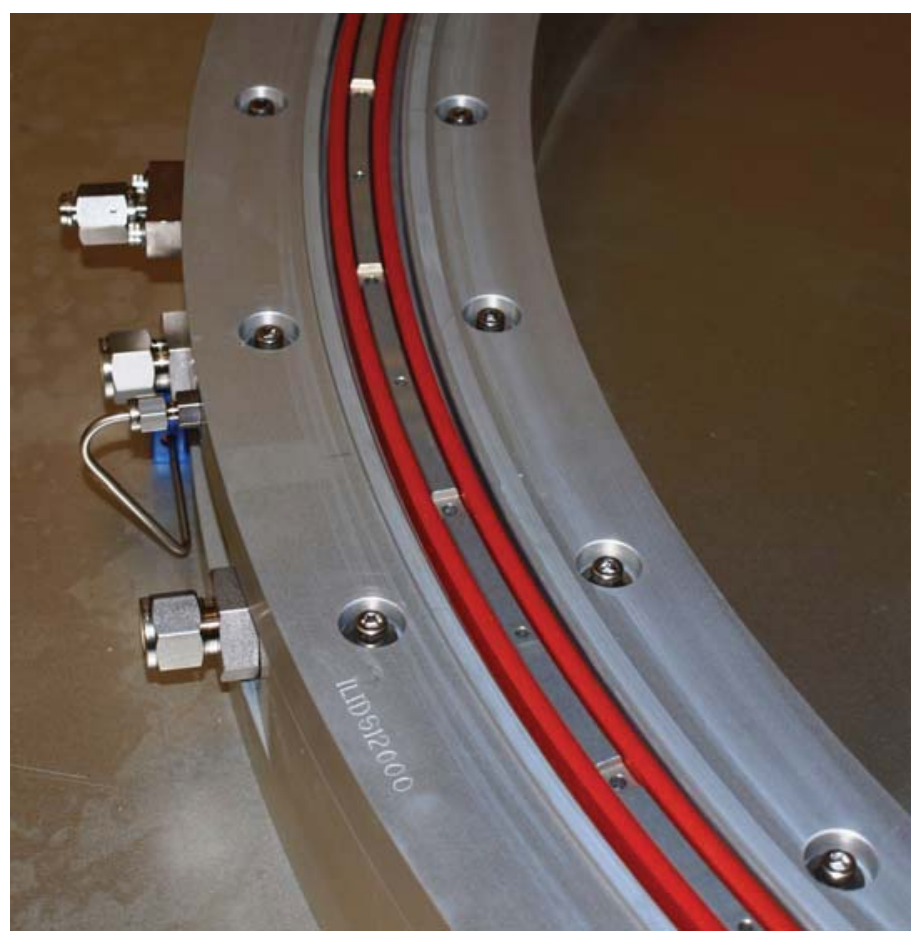

Figure 21. Full-scale seal installed in lower test assembly of full-scale seal leak test fixture. 
The test apparatus is capable of operating over a range of temperatures from -67 to $212^{\circ} \mathrm{F}\left(-55\right.$ to $\left.100^{\circ} \mathrm{C}\right)$. The desired thermal conditions for a given test are achieved mainly by a pair of heat exchanger plates installed on the back side of each test assembly. A Two Loop Chiller/Heater, Model 2VLH30W produced by Mydax, Inc. (Auburn, CA) circulates Syltherm HF heat transfer fluid through the plates during testing to heat or cool the test apparatus to the appropriate temperature and maintain that temperature for the duration of the test. Additional silicone heating elements installed on the external surfaces of the test assemblies augment the heat transfer fluid to achieve the warmest test conditions. An enclosure around the testing zone minimizes the formation of frost and ice on the test specimen and fixture during testing at cold temperatures.

Like the medium-scale test setups, leakage measurements can be made for either the inner or outer seal bulb.

Ports inboard, outboard, and between the seal bulbs allow the leak rate for either seal to be measured with a nominal pressure differential of $14.7 \mathrm{psid}$ across it with the pressure source inboard of the seal and vacuum conditions on the outboard side. Instrumentation located throughout the test apparatus records pressures and temperatures to quantify seal performance during testing. The differential pressure across the test seal is measured by a series of pressure transducers located inboard and outboard of the seal. The pressure on the high pressure side of the test section is monitored using pressure transducers rated for pressures of 0 to $35 \mathrm{psia}$ ( 0 to $241 \mathrm{kPa}$ ) with a specified accuracy of $\pm 0.75 \%$ of full scale. The pressure on the low pressure side of the test section is monitored by vacuum transducers with a range of 0.0001 to 100 torr $\left(1.33 \times 10^{-5}\right.$ to $\left.13.3 \mathrm{kPa}\right)$ with accuracies of $\pm 5 \%$ in the 0.001 to 100 torr range and $\pm 10 \%$ in the 0.0001 to 0.001 torr range. A barometric pressure transducer (accuracy of $\pm 0.00737 \mathrm{psi}$ ) measures the atmospheric pressure in the laboratory during testing. Seal temperatures are measured by 24 equally spaced type $\mathrm{T}$ thermocouples $\left( \pm 0.036^{\circ} \mathrm{C}\right.$ accuracy) divided equally between the two test assemblies.

The test setup is capable of performing leak tests using either air or helium. As with the other leak test setups, air leak tests are performed using a pressure decay methodology, and the leak rate of each test specimen is quantified using the mass point leak rate technique with comprehensive error analysis. ${ }^{6,7}$ For helium leak tests, seal leak rates are measured directly using a helium leak detector.

Additional information about this test apparatus can be found in the paper by Dunlap et al. ${ }^{14}$

\section{B. Full-Scale Seal Compression, Adhesion, and Leak Test Fixture}

Full-scale seal compression and adhesion tests are performed in the test rig shown in Fig. 22. This setup consists of a specially-designed test fixture integrated into a custom Instron SATEC Series 600KN hydraulic load frame. Loads are applied to seal test specimens by an overhead mounted hydraulic actuator capable of generating up to $112,500 \mathrm{lbf}(500 \mathrm{kN})$ in compression and 18,000 lbf $(80 \mathrm{kN})$ in tension. The test fixture is similar to that for the fullscale seal leak test fixture in that it is composed of upper and lower test assemblies made of anodized aluminum. Like the leak test fixture, this test rig is capable of performing tests in both the seal-on-flange and seal-on-seal configurations. For seal-on-flange testing, the seal test specimen is installed in the lower test assembly, and the flat, $16 \mu$ in. sealing surface is on the upper assembly. For seal-on-seal testing, a different upper test assembly is used with a seal installed in it.

The same Mydax 2VLH30W chiller/heater used for the full-scale seal leak test fixture circulates Syltherm HF heat transfer fluid through the upper and lower test assemblies during testing to heat or cool it over a range of temperatures from -58 to $203^{\circ} \mathrm{F}\left(-50\right.$ to $\left.95^{\circ} \mathrm{C}\right)$. Four $50,000 \mathrm{lbf}$ load cells mounted below the lower test assembly measure seal compression and adhesion loads during a test, and the amount of compression applied to the seal is measured by a pair of Heidenhain linear encoders mounted on the sides of the load frame with an accuracy of $+/$ 0.0002 in. A humidity enclosure around the testing zone minimizes the formation of frost and ice on the test specimen and fixture during testing at cold temperatures.

This test fixture is also capable of performing simplified leak tests using air. During these tests, the region between the two seals is pressurized to $2 \mathrm{~atm}$ while the regions inboard and outboard of the seals remain at $1 \mathrm{~atm}$. Combined leak rates for the inner and outer seals are then measured. This functionality allows the effects of load cycling and long-term compression to be evaluated for full-scale seals without having to remove the seal from the test rig for leak testing.

Additional information about this test apparatus can be found in the paper by Dunlap et al. ${ }^{15}$ 


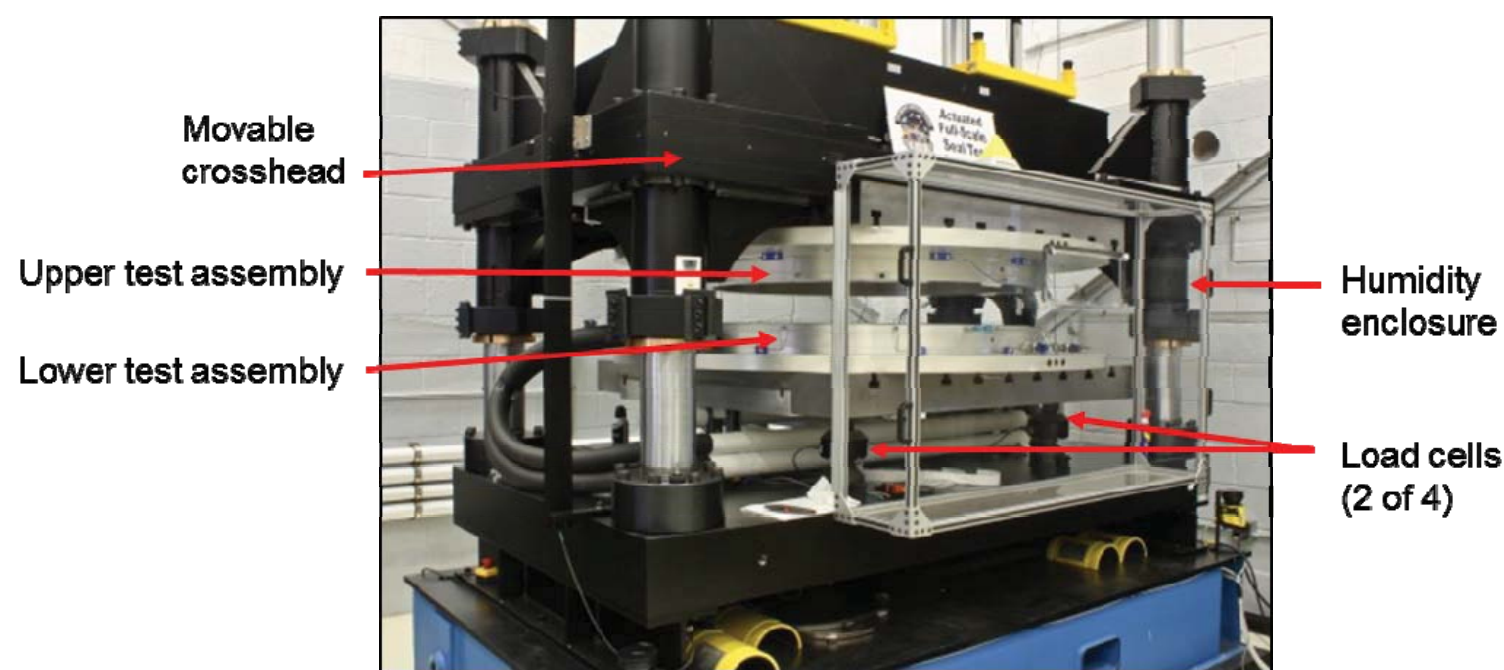

Figure 22. Full-scale seal compression/adhesion test fixture.

\section{Summary}

NASA is developing advanced space-rated elastomeric seals for future space exploration missions including seals for a new docking system and for vehicle hatches. These seals must exhibit extremely low leak rates to ensure that astronauts have sufficient breathable air for extended missions. Seal compression loads must be below prescribed limits to minimize seal compression mechanism mass and loading, and seal adhesion forces must be low to allow the sealed interface to be separated without damage when required (e.g., during undocking or hatch opening). NASA GRC has developed a number of unique test fixtures to measure the leak rates and compression and adhesion loads of candidate seal designs under simulated thermal, vacuum, and engagement conditions. The test fixtures are designed with the flexibility to accommodate future candidate seal designs required to support NASA's ongoing missions for deep space exploration. Small-scale seal test fixtures are used to perform material screening tests on O-rings and other small material samples to help select the final seal material for an application. Mediumscale seal test fixtures are used to test subscale versions of larger seal designs and other seal designs that are on the order of 12 in. in diameter. Full-scale seal test fixtures permit testing of seals on the order of 50 in. in diameter under representative operating conditions. Test conditions for this collection of test fixtures include temperatures ranging from -238 to $662^{\circ} \mathrm{F}\left(-150\right.$ to $\left.350^{\circ} \mathrm{C}\right)$, operational pressure gradients, and seal-on-seal or seal-on-flange mating configurations. Nominal and off-nominal conditions (e.g., incomplete seal compression) can also be simulated.

\section{Acknowledgments}

The author would like to thank the International Low Impact Docking System team from NASA Johnson Space Center for their financial support for the development of the test fixtures described in this report. The author would also like to acknowledge the many team members from NASA GRC, Analex Corporation, QinetiQ North America, Vantage Partners, LLC, the University of Akron, the University of Toledo, Ohio Aerospace Institute, and Gilcrest Electric \& Supply Company who contributed to the design, fabrication, installation, and operation of the test fixtures described in this report.

\section{References}

1 “C-1 Common Berthing Mechanism System Brief,” JSC-36333 Vol. 2, 15 April 2005.

${ }^{2}$ Dunlap, P.H. and Steinetz, B.M., "A Comparison of Candidate Seal Designs for Future Docking Systems," NASA/TM-2012-217722, AIAA-2012-4075, September 2012.

${ }^{3}$ Parker O-Ring Handbook, ORD 5700, Parker Hannifin Corporation, Cleveland, OH, 2007.

${ }^{4}$ Bastrzyk, M.B., Daniels, C.C., Oswald, J.J., Dunlap, P.H., and Steinetz, B.M., "Material Properties of Three Candidate Elastomers for Space Seals Applications," NASA/TM—2010-216263, May 2010.

${ }^{5}$ de Groh, H.C., Daniels, C.C., Dever, J.A., Miller, S.K., Puleo, B.J., Waters, D.L., Finkbeiner, J.R., Dunlap, P.H., and Steinetz, B.M., "Space Environment Effects on Silicone Seal Materials," NASA/TM-2010216332/REV1, January 2013. 
${ }^{6}$ Garafolo, N.G. and Daniels, C.C., "Comprehensive mass point leak rate technique. Part I: Methodology with uncertainty and experimental error analysis" in JSNDI/ASNT Fourth Japan - US Symposium on Emerging NDE Capabilities for a Safer World, Maui, Hawaii, 7-11 June 2010.

${ }^{7}$ Daniels, C.C. and Garafolo, N.G., "Comprehensive mass point leak rate technique. Part II: Application of methodology and variable influences" in JSNDI/ASNT Fourth Japan - US Symposium on Emerging NDE Capabilities for a Safer World, Maui, Hawaii, 7-11 June 2010.

${ }^{8}$ de Groh III, H.C., Miller, S., Smith, I., Daniels, C.C., and Steinetz, B.M., "Adhesion of Silicone Elastomer Seals for NASA's Crew Exploration Vehicle,"NASA/TM-2008-215433, October 2008.

${ }^{9}$ Garafolo, N.G., Bastrzyk, M.B., and Daniels, C.C., "The Effects of Atomic Oxygen on the Sealing and Mechanical Performance of an Elastomer Seal,” AIAA-2010-1440, January 2010.

${ }^{10}$ Panickar, M.B., Wasowski, J.L., and Daniels, C.C., "Adhesion of an Elastomer Seal to Metal and its Mitigation with Atomic Oxygen Pretreatment," AIAA-2011-0426, January 2011.

${ }^{11}$ Oravec, H.A., Garafolo, N.G., and Daniels, C.C., "The Mechanical and Sealing Performance of an Atomic Oxygen Pretreated Subscale Candidate Silicone Elastomer Docking Seal,” AIAA-2013-3838, July 2013.

${ }^{12}$ Conrad, M.C., Daniels, C.C., and Bastrzyk, M.B., "An Experimental Investigation of Silicone-to-Metal Bond Strength in Composite Space Docking System Seals," AIAA-2009-5318, August 2009.

${ }^{13}$ Dunlap, P.H., Martin, R.E., Garafolo, N.G., Oravec, H.A., and Steinetz, B.M., "Durability Testing of Docking System Seals for Space Applications," AIAA-2011-5710, August 2011.

${ }^{14}$ Dunlap, P.H., Daniels, C.C., Steinetz, B.M., Erker, A.H., Robbie, M.G., Wasowski, J.L., Drlik, G.J., Tong, M.T., and Penney, N., "Full-Scale System for Quantifying Leakage of Docking System Seals for Space Applications," NASA/TM-2007-215024, AIAA-2007-5742, October 2007.

${ }^{15}$ Dunlap, P.H., Steinetz, B.M., Daniels, C.C., Wasowski, J.L., Robbie, M.G., Erker, A.H., Drlik, G.J., and Mayer, J.J., "Full-Scale System for Quantifying Loads and Leak Rates of Seals for Space Applications," NASA/TM- 2010-216885, AIAA-2010-6987, December 2010. 